\title{
Fractal Reflection: Cultivating Community and Meaning in Times of Crises
}

\author{
Deandra Little, Joshua Caulkins, Eric C. Kaldor, and \\ Lindsay Wheeler
}

\begin{abstract}
The Pandemic Educational Development Research Collaborative (PEDRC) formed in April 2020 to record research-participants' experiences during the COVID-19 pandemic and systemic racism crises and includes 18 educational developers across various 4-year institutions, types of centers, and positions in the field. The novel research methodology used by PEDRC, called "fractal reflection," includes an iterative process of reflection, analysis, and meaning-making at the individual, paired, and group levels. However, this methodology served as more than just a means to collect data; it also provided a set of effective reflective practices to support educational developers managing the emotional labor of their work in times of crises. In this article, we describe our method of "fractal reflection" and discuss the findings from and benefits of this process. We connect our process to the literature of reflective practice and conclude with some key characteristics of reflective practice that others can use to integrate fractal reflection methodologies into their work.
\end{abstract}

Keywords: reflection, research methodologies, community of practice, emotional labor

I remember where I was when I was notified that we would be moving to online teaching. I was in the middle of running a 2-day workshop on Collaborative Learning. (Respondent A, Log 1) 
[W]e started sharing resources wildly and widely (before we learned that was overwhelming, because suggestions were coming fast and furious from everywhere, with no triage) before we shifted . . from firehose to curation of resources. (Respondent B, Log 1)

Prior to March 2020, as educational developers, we offered services, programs, or projects designed to transform some aspect of teaching and learning at our institutions. Typically, the timeline for planning and implementing these programs was weeks to months long, and the size of programs was partly determined by our ability to provide adequate support. That changed overnight with the COVID-19 pandemic to a model resembling medical triage. Hundreds of instructors needed critical support in a short number of days, and we had to scramble to develop relevant offerings-frequently on new-to-us topics-rapidly. Our faculty colleagues needed to immediately transition to video conferencing software, online assessment techniques, online teaching tools and technology, and methods of student engagement and support that were, until that time, something only "other" faculty did. This intense refocusing of our work created feelings of fatigue and anxiety and often a sense of being overwhelmed by the efforts needed to support our colleagues and their students. Along with this shift in focus came continuous (and changing) articulations of new priorities, all of which elevated levels of stress for each of us and for educational development colleagues in our networks. Layered on top of these shifts, we experienced an increase in the emotional labor needed in our work coupled with attempts to remain positive, encouraging, and calming with faculty, students, and colleagues as we walked this unknown path together. A central challenge for the four of us has been how to cope with the emotional and psychological strain while sustaining work we deeply value.

When we came together with other colleagues as part of the Pandemic Educational Development Research Collaborative (PEDRC), we 
thought that studying our work during the pandemic could result in useful contributions to the field. In the process, we discovered that our novel research methodology-which we are calling "fractal reflection"-provided more than just a means for data collection. It also introduced a set of effective reflective practices that served as a processing mechanism for us as educational developers in times of crises. This article shares insights from research conducted by the PEDRC, a group of 18 educational developers working together to reflect on and document their work during the COVID-19 pandemic. The PEDRC includes colleagues from various 4-year institutions, U.S. regions, and career positions in the field. Below we describe how we enacted a continued process of reflection in our methodology. We then discuss the findings from and benefits of this process and conclude with some key characteristics of reflective practice that others can use to integrate fractal reflection methodologies into their work.

\section{Our Methodology}

Our fractal reflective methodology was designed by authors Kaldor and Wheeler as a structured version of ethnographic research, in which researcher-participants are asked to routinely log observations and reflections on their work and their wider academic and social contexts while also gathering specific information and artifacts to help compare experiences across the institutions. While highly decentralized, the research methodology called for collaborative work including analyses in pairs, occasional research debriefing meetings, and dissemination writing teams. In each aspect of the research process, we were continually reflecting and making meaning from conversations around our shared experiences. This fractal reflective process (Figure 1), which we describe more in detail below, has resulted in positive-some unintendedconsequences for the researcher-participants of the PEDRC.

As illustrated in Figure 1, our fractal reflective methodology utilizes a cyclical process of reflection, analysis, and meaning-making that 


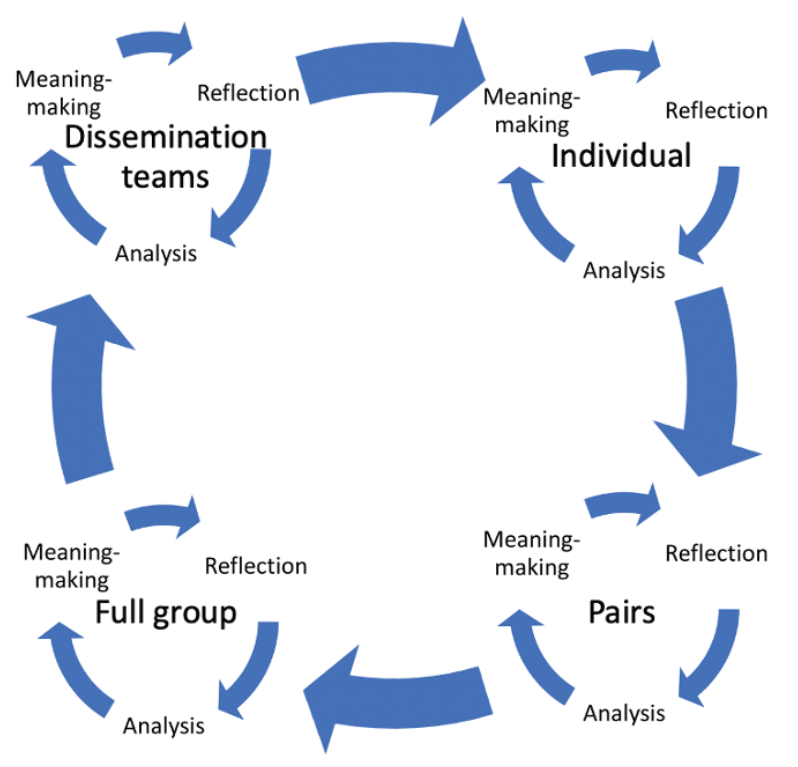

Figure 1. The fractal reflective process used by the PEDRC

Note. This fractal reflective process is represented in two dimensions. Not pictured is the three-dimensional spiraling nature of the iterative process, wherein the dissemination teams' process leads to further individual reflection at a new and different level than before.

repeats at the individual, pairs, group, and dissemination levels. As an example, we started the individual fractal reflection process in May 2020 when we as researcher-participants each completed weekly logs. In the first log, we retrospectively reflected on our experience with the rapid transition to online instruction during the spring semester. In the next six weekly logs, we described our work and changing priorities, feelings about work and personal lives, interactions with colleagues, and reflections on what the future holds. In June, a fifth question was added to the other prompts in recognition of the ways that the pandemic was intersecting with other social crises around systemic racism and social inequality. For 4 weeks, participants were asked to reflect on their experiences around the nationwide Black Lives Matter protests following George Floyd's killing. 
After 6 to 7 weeks, we individually reread and analyzed our past logs to identify important themes and draw meaning from our earlier writings. As part of the paired fractal reflective process, we each had a coding conversation with one other researcher-participant to compare and contrast themes and share concrete examples from our individual logs. As a pair, we documented these conversations in analytic memos and developed new themes from the discussion. To end the paired meeting, we reflected back on the process and our experience in the process thus far.

Once the paired conversations were complete and the analytic memos collected, the lead researchers then coded the memos from all pairs to identify important themes for the entire team to reflect on. During full group research meetings, we engaged in further fractal reflection by identifying and discussing promising insights that further deepened our understanding of the data and our experiences. These insights led to identification of particular stories we wanted to share, and various dissemination teams formed to spearhead the writing process. As each dissemination team worked to create their story, they engaged in yet another fractal reflective process. In these teams, further insights and meaning-making occurred about the process and the product of our fractal reflection, and teams began connecting those themes to the broader field of educational development research and practice. For example, this article shares the story of the reflection, analysis, and meaning-making of our methodology.

\section{Early Results: Findings Intersect}

One of the first findings to come from our analysis of pairs' memos was a recognition of how prominently discussions of emotional responses figured in all our accounts of working and living through the first wave of the pandemic. Researcher-participants reported a wide variety of emotions often tied to unique contexts and positionality. Emotional responses ranged from feelings of exhaustion, frustration, regret, sad- 
ness, guilt, anxiety, and hopelessness to those of gratitude, humility, hope, optimism, and joy. Negative and positive emotional responses easily coexisted in the same logs. Negative emotions were often driven by constant change and uncertainty at home and at work, managing work-life balance, and the needs and demands of others (i.e., family, colleagues, community). Participants described a variety of strategies to manage these negative emotions, including compartmentalizing, reorganizing priorities, letting things go, and attempting to self-care. The more positive emotions were often related to connections with others (e.g., support from colleagues at other institutions or more time with children). Many also noted positive emotions stemming from the particular value of their educational development work in the moment.

A second finding from the thematic analysis was unexpected: pairs noted that different steps in the research process had been useful for them during the period of rapid transition to remote instruction. Although brief in their descriptions, 8 of the 9 coding pairs used words such as useful, helpful, illuminating, and revealing. Some brief quotes from different pairs' memos provide a sense of how the fractal reflective research process was beneficial for participants:

Reading back allowed emotions to be accepted and to take a researcher stance. (Pair 1, July 2020)

The similarity in the themes even when our perspectives or examples were different. After the very first theme [researcher's name] described, [partner's name] laughingly copy-and-pasted hers into the document because the phrases (multiple!) were exactly the same. (Pair 4, July 2020)

Really affirming. Helpful to hear from someone else going through the same things at a different institution! (Pair 5, July 2020)

Finally, we agree that the opportunity to write, reflect, and share is especially helpful during these difficult times. We agreed that we 
probably would not have recorded our thoughts about the experience if we did not have this project. (Pair 6, July 2020)

It was only when we surfaced these two preliminary findings with the full team in July that participants began to speak more explicitly about how valuable the research process had been for our well-being in this challenging time, particularly in navigating some of the more challenging emotional dimensions of our work. This led us as co-authors to carefully reexamine our own experiences using this reflective methodology and consult the wider literature on the use of reflective writing in similar professional settings to understand the value of our process.

\section{Revisiting our Method: Benefits of Fractal Reflection}

[T]he busier we are, the more reflective we need to be. That is, the more pressure we are under, the clearer we need to be about what we are doing, why we are doing it, what knowledge is available to help us do it to best effect, and so on. (Thompson \& Pascal, 2012, p. 320)

As we entered this final stage of meaning-making as co-authors, several questions surfaced: What is it about the act of prompted reflectionand, ultimately, the reviewing, sharing, and discussing of those reflections with peers-that makes it such a valuable exercise? What do we gain from this reflection and exchange? In what ways does it help us become better at our work and/or dealing with the challenges we face in our professional and personal lives? On one level, these questions about the value of reflection for professional meaning-making are not new. Reflection is an established practice for professional identity formation and lifelong learning in many of the helping professions; it is often explicitly part of undergraduate or graduate training, such as, for example, in medical (e.g., Wald et al., 2019) and nursing education (e.g., Goulet et al., 2016; Nelson, 2012), social work (e.g., Gould \& Taylor, 1996), and K-12 teacher preparation (e.g., Hatton \& Smith, 1995). The 
literature on reflective practice also details different formats for this practice, including writing, audio or video recordings by individuals (Moon, 2004), and interactive "meta-reflection" in dyads or groups (Thorpe \& Garside, 2017; Wald et al., 2019).

In higher education teaching, reflection is discussed both as a practice for instructors to adopt for their own professional development (Brookfield, 2017) as well as a type of thinking for faculty to impart to students to improve metacognition or to prompt integrative learning in experiential learning pedagogies (Moon, 2004). In our own educational development work, we often prompt faculty or graduate student colleagues to engage in thinking about their own teaching or their students' learning in ways akin to Dewey's (1933) concept of "critical reflection" or Schön's (1983) theory of "reflection in action" (thinking about a professional practice or experience while doing it) and "reflection on action" (connecting that experience with other knowledge). Often, we do this in the belief that reflection can lead to beneficial change, learning, or transformation (Mezirow, 1991).

Encouraging reflective practice is something we routinely do as developers, whether or not explicitly by name. Across professional contexts, specific definitions of reflection vary, though there are shared common elements, including attempts to explain how reflection is distinguished from other types of thinking. Two definitions that attempt to synthesize across the literature bear repeating here: (a) Moon's (2004) "common-sense" definition of reflection as a "form of mental processing . . . applied to relatively complicated, ill-structured ideas for which there is not an obvious solution and is largely based on the further processing of knowledge and understanding that we already possess" (p. 82); and (b) Nguyen et al.'s (2014) operational definition and model developed through systematic review of the 15 authors ( $p$. 1179) most frequently cited in articles on reflection published between 2008 and 2012: "Reflection is the process of engaging the self in attentive, critical, exploratory and iterative interactions with one's thoughts and actions, and their underlying conceptual frame, with a view to changing them and with a view on the change itself" (p. 1182). 
As we made meaning from connecting our fractal reflective process to this research literature, we recognized three commonalities in what was most valuable about the process: (a) feeling unburdened by taking the time to reflect on our experiences and connect with others; (b) a sense of validation and catharsis, centered on the experience of being heard by a colleague who understands the higher education context, especially as it relates to educational development work; and (c) the normalization or routinization of working in a time of change and uncertainty. Interestingly, this conversation helped us better articulate why our connection to this project was so powerful.

In alignment with the literature that reflection prompts action (Mezirow, 1991) and reflection in action (Schön, 1983), when we reviewed some of our older log entries with some distance, it became clear that structured reflection often encouraged us to process our feelings and emotional responses. For example, notice how the writer in the following log entry from June 2020 shifted from a series of reflective observations to drawing conclusions on how they might act going forward:

I find myself constantly controlling and not sharing how I'm feeling. Caring for others on my team, colleagues. I need to find some balance in all of this, but I run to help in this space. My most common approach now is to remind myself that everyone around me is potentially bearing trauma as they respond and react. I need to slow things down and be a caring person for others, maybe this will help me also manage my more explosive emotional responses. (Respondent C, Log 4)

This kind of step toward establishing habits for managing a new level of emotional labor was possible at the individual level, and we routinely found that the structured conversations in pairs added needed perspective to better understand our own situation and the wider context, a practice of reflection on action (Schön, 1983) as well as metareflection (Thorpe \& Garside, 2017; Wald et al., 2019). This was well illustrated by a conversation one of us had with a coding partner. Dur- 
ing the conversation one participant described the experience of heightened visibility in a large university and an increased value for educational development, whereas the other described the silencing, demotion, and devaluing of their center and position during the pandemic. This conversation created a space for each to validate the powerful impact of their experiences on their professional identity and well-being. Despite their institutional differences, they found commonality around their increased participation in professional networks and shared values around their equity and anti-racist work in their respective roles.

\section{Practical Suggestions for Engaging in Fractal Reflection}

As illustrated in Figure 1, the PEDRC engaged in continuous fractal reflection throughout the four different levels of our research (i.e., individual, pairs, full group, dissemination teams); however, this extensive process may not be practical for many educational developers. As we analyzed our PEDRC research methodology and its benefits, we identified that a structured and layered process of reflection, analysis, and meaning-making—the "fractal unit"—would be most important to help others navigate this time of uncertainty and manage the emotional labor of our work. We will now review concrete strategies for each component of the fractal unit that educational developers can integrate into their own practice.

First, and perhaps the most challenging, is purposefully taking the time to pause and reflect. This allows you to think iteratively about your own thoughts, feelings, and actions and can be beneficial as a "distancing function" (Thorpe \& Garside, 2017, p. 113). We found that setting aside 30 minutes of writing time and having colleagues that you feel accountable to for reflection are vital. Taking the time to write gave us a sense of "unburdening" ourselves so we could focus on our work, family, and other needs. We recommend recruiting a colleague or small group of educational developers to join you in finding time to 
individually reflect on a bi-monthly or monthly basis (for our reflective prompts, see https://sites.google.com/view/pedrc).

Second, structured analysis can prompt movement beyond surfacelevel description or rumination to allow you to critically engage with your assumptions or "underlying conceptual frame" (Nguyen et al., 2014). One relatively simple approach we have used is to review previous logs and reflect on the experience of reading these documents or noting thematic concerns. We found it particularly challenging to read our first log and valued being able to process those feelings. Analysis can also occur in discussion with others, when conversation partners may note themes, commonalities, and differences, engaging together in a process of meta-reflection (Thorpe \& Garside, 2017). This paired analysis allows each individual to analyze and return to the experience in a different way. Having peer discussions with other educational developers-whose skill set includes the ability to actively listenabout reflective writing is also extremely beneficial. These paired reflections require attentive listening, which adds a layer of empathy, experience checking, and the sensation of being validated and heard. However, it is important to consider both the identity and positionality of yourself and your colleague and to pay attention to someone else's experience and not just your own.

Third, meaning-making allows for exploration into how the "trigger" or "context" (Nguyen et al., 2014) for the reflection contributes to or shapes the content of the reflection or the process of reflecting. It can also help educational developers cope with an increased workload, recenter important values and priorities, or reexamine problematic assumptions. We recommend taking time to identify what you are learning about yourself, others, and/or your context that enable you to manage during times of crises. Engaging in meaning-making in a community can also help normalize the feelings and responses you may be having to the constant change and uncertainty and help create a shared understanding of themes or ideas from the analysis process. We recommend setting up discussion expectations that include candor and confidentiality to ensure these discussions are meaningful and productive. 


\section{Conclusion}

While our contexts and experiences were not identical, the challenges, fears, and changing landscape of our work reminded us that we were not alone, that others felt the same way, and that this knowledge was valuable and important. Our colleagues witnessed our experiences and validated them, recognizing the strain we were feeling and describing their own stresses, challenges, and moments of despair. The validation and act of being heard by another colleague on this project, often someone we had never previously engaged with before, provided each of us with a feeling of purpose and strength we had not felt previously. We felt we could move forward and continue to help our faculty, students, and peers without being overwhelmed. During a time of intense and extended pressure, the structured and layered fractal reflective process helped us process our own experiences and emotions, attend to our well-being, and keep moving forward with work we value deeply. We hope you feel empowered to invite a colleague to engage in fractal reflection.

\section{Acknowledgments}

We would like to acknowledge all of the other 14 PEDRC members, who have been engaged in this reflective, meaning-making process alongside us: https://sites.google.com/view/pedrc.

\section{Biographies}

Deandra Little, PhD, is Assistant Provost and Director of the Center for the Advancement of Teaching and Learning and Professor of English at Elon University, North Carolina. She works with faculty and teaching staff to foster evidence-informed, inclusive, and innovative 
teaching and learning practices and the scholarship of teaching and learning. Her research and publications focus on the scholarship of educational development and teaching and learning.

Joshua Caulkins is Director of the Center for Teaching and Learning Excellence at Embry-Riddle Aeronautical University in Prescott, Arizona, where he supports all course and curriculum redesign efforts, the adoption of inclusive pedagogy and evidence-based teaching practices, and the promotion of backward design processes at all levels of the institution. His contribution to this article occurred while he was at Arizona State University, serving as the Assistant Director for Undergraduate Programs in the School of Life Sciences, in Tempe, Arizona.

Eric C. Kaldor, PhD, is the Senior Associate Director for Assessment and Interdisciplinary Teaching Communities at Brown University's Sheridan Center for Teaching and Learning, where he supports actionoriented assessment of student learning and educational development programs. He also facilitates programs for faculty and graduate students that emphasize developing and sustaining interdisciplinary communities of practice around teaching. His past research projects have explored strategies to develop students' metacognition, intercultural mindsets, and motivation around writing.

Lindsay Wheeler, PhD, is Assistant Director of STEM Education Initiatives and Assistant Professor in the Center for Teaching Excellence at the University of Virginia. Her research examines the impact of educational development interventions and evidence-based teaching practices on instructors, classroom instruction, and student learning. She has also published studies on her project-based guided inquiry (PBGI) chemistry laboratory curriculum and associated professional development for teaching assistants. 


\section{References}

Brookfield, S. D. (2017). Becoming a critically reflective teacher. John Wiley \& Sons.

Dewey, J. (1933). How we think: A restatement of the relation of reflective thinking to the educative process. D. C. Heath.

Gould, N., \& Taylor, I. (1996). Reflective learning for social work: Research, theory and practice. Ashgate.

Goulet, M.-H., Larue, C., \& Alderson, M. (2016, April). Reflective practice: A comparative dimensional analysis of the concept in nursing and education studies. Nursing Forum, 51(2), 139-150. https://doi.org/10.1111/nuf .12129

Hatton, N., \& Smith, D. (1995). Reflection in teacher education: Towards definition and implementation. Teaching and Teacher Education, 11(1), 33-49. https://doi.org/10.1016/0742-051X(94)00012-U

Mezirow, J. (1991). Transformative dimensions of adult learning. Jossey-Bass.

Moon, J. A. (2004). A handbook of reflective and experiential learning: Theory and practice. RoutledgeFalmer.

Nelson, S. (2012). The lost path to emancipatory practice: Towards a history of reflective practice in nursing. Nursing Philosophy, 13(3), 202-213. https:// doi.org/10.1111/j.1466-769X.2011.00535.x

Nguyen, Q. D., Fernandez, N., Karsenti, T., \& Charlin, B. (2014). What is reflection? A conceptual analysis of major definitions and a proposal of a fivecomponent model. Medical Education, 48(12), 1176-1189. https://doi.org $/ 10.1111 /$ medu. 12583

Schön, D. A. (1983). The reflective practitioner: How professionals think in action. Basic Books.

Thompson, N., \& Pascal, J. (2012). Developing critically reflective practice. Reflective Practice, 13(2), 311-325.

Thorpe, A., \& Garside, D. (2017). (Co)meta-reflection as a method for the professional development of academic middle leaders in higher education. Management in Education, 31(3), 111-117. https://doi.org/10.1177/08920 20617711195

Wald, H. S., White, J., Reis, S. P., Esquibel, A. Y., \& Anthony, D. (2019). Grappling with complexity: Medical students' reflective writings about challenging patient encounters as a window into professional identity formation. Medical Teacher, 41(2), 152-160. https://doi.org/10.1080/0142159X .2018.1475727

To Improve the Academy • Vol. 39, No. 3 • Spring 2021 